АТОМНА ЕНЕРГЕТИКА

ATOMIC ENERGY

УДК 621.387 .426

https://doi.org/10.15407/jnpae2018.03.237

\author{
A. L. Ulybkin ${ }^{1 *}$, A. V. Rybka ${ }^{1}$, K. V. Kovtun ${ }^{1}$, V. E. Kutny ${ }^{1}$, V. N. Voyevodin ${ }^{1,2}$, A. O. Pudov ${ }^{1}$ \\ ${ }^{I}$ National Science Center "Kharkov Institute of Physics and Technology", \\ "Institute of Solid State Physics, Materials Science and Technologies", Kharkiv, Ukraine \\ ${ }^{2}$ V. N. Karazin Kharkiv National University, Kharkiv, Ukraine \\ *Corresponding author: a.ulybkin@gmail.com
}

\title{
COMPTON-EMISSIVE HAFNIUM DETECTOR OF NEUTRONS FOR IN-CORE MONITORING
}

\begin{abstract}
The work is devoted to substantiating the use of metallic hafnium as the emitter of the Compton (prompt-response) in-core detector of thermal and resonant neutrons. The main trends in the development of nuclear power engineering, which raise the interest in the use of hafnium, are considered. The known data on the behavior of both Compton and $\beta$ emission self-powered neutron detectors (SPND) are generalized. The Compton SPND signal formation mechanism for the case of the irradiation by reactor-type fluxes of neutrons and gamma quanta is considered. The paper presents the calculation result of the hafnium burning-out degree for the conditions of WWER and RBMK reactors. The influence of the gamma radiation "sources", which provide the largest contribution to the electrons production in the detector is considered.
\end{abstract}

Keywords: nuclear energy, neutron detector, hafnium, prompt response, energy yield, control, radiation resource.

\section{Introduction}

The reasons why the use of hafnium once again shows great promise are not only due to Hf nuclearphysical characteristics. The timeliness of this material's application also lie in the general trends of the development of the world nuclear industry. These questions have already been partlyraised in $[1,2]$. In general, hafnium has long proved itself as a material that is possible to use and needs to be used in the nuclear industry (for example, as a material for control rods) [3, 4]. The present studies are in the field of solving tasks in improving the safety and economy of pressurized water reactors through the development of in-core measurement systems with autonomous neutron detectors (SPND for neutron flux monitoring).

The aim of the research is the creation of the fastresponse SPND, which can be used in Reactor Control and Safety System (RCSS) for monitoring and controlling of the neutron field. The main task of using such detector it is the energy release irregularity reducing of the reactor core.

The intensity of heat release in a FA is theoretically unlimited. This feature is used to select the maximum permissible heat dissipation (energy release) $q$ with a reserve for possible deviations from the nominal level:

$$
q \leq q_{\text {critical }}-\Delta q_{\text {reserve }} \text {. }
$$

The thermal load $q$ on a fuel element (FE) surface is a very important parameter and is determined by the following: 1) the design of the FE; 2) the concentration of fissile isotopes in the fuel; 3) the neutron flux density profile. The temperature and its gradients (in the heat-releasing layer of the coolant, which cools the FE) depend on $q$. The critical thermal load $q_{\text {critical }}$ predetermines the energy release level of the FE, at which the crisis of heat transfer begins. In this case, the most dangerous stage is when the bubble boiling of the coolant on the surface of the FE transforms to the film boiling (bubble boiling crisis) [5, 6, 27]. Above the starting temperature of the surface boiling, the volume density of the coolant decreases due to the formation of vapor bubbles in it. In the case of surface boiling, the bubbles can merge and the interphasic layer on a border "FE-coolant" is created. This greatly increases the intensity of corrosion processes, which affects the reliability of the FE. Surface boiling is important in connection with the provocation of early cracking (loss of hermiticity) of the cladding, and the ingress of fission products into the coolant circuit. The latter significantly increases the specific activity of the coolant, which can bring about the inability to operate the reactor [7]. The lifetime of the bubbles depends on the temperature and pressure of the coolant. The change in the coolant density affects the neutron moderation ratio. In this case, the amplitude of the coolant density oscillations increases substantially, which leads to an increase in the noise in the energy spectrum of the neutron flux.

(C) A. L. Ulybkin, A. V. Rybka, K. V. Kovtun, V. E. Kutny, V. N. Voyevodin, A. O. Pudov, 2018 
There appears a spatial instability of energy release, which should be eliminated. That is why the normal operation and safety of a nuclear reactor is impossible without systems for monitoring and controlling the processes taking place in its core.

The constant necessity for greater reliability, safety, efficiency, higher fuel burn-up and the campaign prolongation for nuclear power plants lead to the need of the use of new materials for elements of energy-yield control system. The most important measurements in nuclear power reactors are the determination of the spatial density of the neutron flux and the generated energy in the reactor core. The importance of these measurements consists in the fact that they are directly related to the operational parameters of nuclear reactors and their power [8].

The task of regulating the energy yield can be solved by controlling the neutron flux density distribution [9]. The use of rhodium SPND will be complicated for the following reasons:

1) at transition to longer fuel cycles, the rhodium SPND will reach the operational limit even before the its end of the service life (3...4 years);

2 ) for reasons of safety, when increasing the core energy release irregularity ratio, it is necessary that the neutron field monitoring is carried out by the detector with a minimum response time, but the rhodium SPND (like any other activation detector) does not fit this requirement [1, 10, 11, 20, 29]. Consequently, it is necessary to create a detector, whose, characteristics (operation life, response time, etc.) are consistent with the current high-level requirements for safety.

The present work is dedicated to the investigation of metallic hafnium as a material of the emitter in the fast-response (Compton) SPND. In the future, such detector is supposed to be used in the in-reactor measuring channels of the ICCS-system of pressurized water reactors. During the reactor operation, the characteristics of the response time and the service life of such SPND type correspond to the new (toughened) operating conditions. The use of the proposed SPND enhances the safety and reliability of operation of various reactor types (WWER, CANDU, RBMK).

\section{Hafnium usage}

As mentioned above, hafnium is not a new material in the nuclear industry [12]. Since the end of the 1950s, it has been successfully used as a material for control elements of reactors on nuclear submarines and in a number of commercial watercooled reactors [14 - 17].

However, limited hafnium production, the imperfection of its production technology and the high final cost of the products led to a temporary abandonment of this material.

In the second half of the 1960s, the most widespread material used in control rods was the alloy $80 \% \mathrm{Ag}+15 \% \mathrm{In}+5 \% \mathrm{Cd}$ (AIC). This alloy has a neutron absorption efficiency comparable to that of hafnium, high thermal conductivity and practically does not swell during irradiation. At the same time, the AIC has a lower corrosion resistance (approximately 20 times), low melting point $\left(\sim 1050{ }^{\circ} \mathrm{C}\right.$; for hafnium, it is $\sim 2220^{\circ} \mathrm{C}$ ) and low mechanical characteristics in comparison with hafnium $[12,13]$.

The accumulation of stock of $\mathrm{Hf}$ (because of zirconium production expansion), its nuclear physical characteristics, corrosion and radiation resistance, improvement of its production technology, experience in working with it, as well as a significant increase in the price of the AIC alloy, again revived interest in hafnium. Now it is considered as a material capable of competing with silver alloys in commercial reactors. In connection with this, the program for swapping the control rods in RCSS system of PWR from AIC to those with alloy composition $95.3 \% \mathrm{Hf}+4.5 \% \mathrm{Zr}+0.2 \%$ impurities was developed by "Westinghouse" company (USA). Such a swapping will leave the design of the control rod cluster in the FA unchanged. In addition, hafnium was used in the 1990s for the manufacture of a pilot lot of control rods at WWER-1000 Rovno Nuclear Power Plant (Ukraine) and Novovoronezh NPP (Russia).

Hafnium also found an application in in-reactor measurement systems. A Compton-type neutron detector with an emitter of hafnium oxide was developed and examined in the 1980s [18 - 21]. It was shown that in terms of its basic characteristics (response, sensitivity, dimensional stability), such detector can be used in RCSS system of RBMK reactors. As a result, SPND with an emitter from hafnium oxide is used as one of the types of detectors for monitoring the energy release along the radii of RBMK reactors [22].

The number of $\mathrm{Hf}$ atoms (atomic concentration) predetermines the detector lifetime and its sensitivity in accordance with the probability of the radiative neutron capture in the (n, $\gamma)$-reaction. The crosssection for calculating the burn-out of atoms looks like:

$$
\hat{\sigma}=\bar{\sigma}+\frac{\Phi_{\mathrm{res}}}{\Phi_{\mathrm{th}}} \cdot I
$$

where $I$ is the effective resonant integral; $\bar{\sigma}$ is the cross-section, taking into account the temperature of environment absorbing neutrons $(k \cdot T$ and the 
Westcott $g$-factor are accounted for); $\frac{\Phi_{\text {res }}}{\Phi_{\text {th }}}$ is the neutron spectrum hardness; $\Phi_{\text {res }}$ is the resonant neutron flux density; $\Phi_{\text {th }}$ is the thermal neutron flux density [24, 25].

The neutron spectrum in the core of the RBMK is characterized by low hardness, which does not exceed the value 0.12 [23]:

$$
\left(\Phi_{\text {res }} / \Phi_{\text {th }}\right)_{R B M K} \leq 0.12
$$

The hardness of the neutron spectrum in the core of WWER reactors is much higher, for example, for WWER-440 it is:

$$
\left(\Phi_{\text {res }} / \Phi_{\text {th }}\right)_{W W E R}=0.23 \ldots 0.73
$$

The number of hafnium atoms contained in $\mathrm{HfO}_{2}$ is significantly smaller in comparison with that in metal:

$$
N_{\mathrm{Hf}}\left(\mathrm{HfO}_{2}\right) / N_{\mathrm{Hf}}(\mathrm{Hf}) \approx 0.62
$$

where $N_{\mathrm{Hf}}\left(\mathrm{HfO}_{2}\right)$ is the $\mathrm{Hf}$ atomic concentration in $\mathrm{HfO}_{2} ; N_{\mathrm{Hf}}(\mathrm{Hf})$ is the $\mathrm{Hf}$ atomic concentration in metallic hafnium. In the case, when $\mathrm{HfO}_{2}$ powder is used, this ratio is even smaller.

The calculation shows that, for a neutron flux at the level of $\sim 10^{14} \mathrm{n} /\left(\mathrm{cm}^{2} \cdot \mathrm{s}\right)$, the different hardness of the spectra leads to the fact that, under the conditions of the WWER reactor, the burn-out of hafnium atoms occurs $\sim 2 . .3$ times faster than in RBMK $(\sim 1.15 \%$ per year for RBMK and $2 \div 3.5 \%$ per year for WWER).

The atomic concentration $N_{\mathrm{i}}$ of neutron-sensitive material determines the flux density of $\gamma$-quanta in the $(n, \gamma)$-reaction:

$$
\Phi_{\gamma}=\Phi_{n} \cdot \sum_{i} \sigma_{i} \cdot N_{i} \cdot k_{i}
$$

where $\Phi_{\mathrm{n}}$ is the neutron flux density, $\mathrm{n} /\left(\mathrm{cm}^{2} \cdot \mathrm{s}\right)$; $\sigma_{\mathrm{i}}$ is the microscopic cross-section - a quantitative characteristic of the probability for particle (in this case it is a neutron) interaction on unit length of a path in a substance with one atom of the i-th type, $\mathrm{cm}^{2} /\left(\right.$ at. $\cdot$ particle); $N_{\mathrm{i}}$ is the atoms number of the irradiated material; $k_{\mathrm{i}}$ is the average number of $\gamma$-quanta, emitted by the i-th isotope upon neutron capture.

At this stage of research, the task is to simplify the physics of the processes that occur. Therefore, a number of assumptions are accepted: all SPND's atoms materials are in equal conditions; fluxes of $\gamma$-quanta and neutrons are monoenergetic, and have a certain directivity. Thus, speaking of the flux density $\Phi_{\gamma}$, we mean only the number of emerging $\gamma$-quanta per unit time, but not the directed and monoenergetic beam.

During the interaction of $\gamma$-quanta with the irradiated material atoms, an electron flux is generated:

$$
\Phi_{\mathrm{e}} / \Phi_{\gamma}=\left(\mu_{\text {Photo }}+\mu_{\text {Compton }}+\mu_{\text {Pair }}\right) \cdot \rho \cdot x,
$$

where $\rho$ is the material density $\left[\mathrm{g} / \mathrm{cm}^{3}\right] ; x$ is the material thickness, $\mathrm{cm} ; \mu$ is the $\gamma$-radiation attenuation factor, $\mathrm{cm}^{2} / \mathrm{g}$.

Thus, the burn-out of the emitter material is directly related with the formation of the detector signal. This means that the use of $\mathrm{HfO}_{2}$ as a neutronsensitive material in WWER reactors is less (not sufficiently) effective for the following reasons: 1) a more intense burnout and a low (in comparison with metallic $\mathrm{Hf}$ ) atomic concentration of hafnium lead to reducing of the $\mathrm{HfO}_{2}$-emitter lifetime; 2) a lower signal level in comparison with metallic hafnium.

The choice of metallic Hf as the emitter material for in-reactor Compton SPND makes it possible to provide a higher signal level, a longer operation life, a decrease in detector dimensions. The last is important from the position of minimal impact on the configurations of neutron fields in the reactor core. In addition, as for any other Compton detector, the main advantage is an instant (prompt) response to any (within the sensitivity) fluctuations in the neutron flux density.

\section{Features of the SPND's signal generation}

The work of electron-emitting neutron detectors is based on $(n, \gamma)$-reaction of radiative capture of neutrons by the nuclei of the atoms in the irradiated material (detector emitter). This reaction leads to the radioactive decay of isomeric metastable levels of the compound nucleus. The excitation of the compound nuclei is removed by means of the $\beta$ particles emission (activation or $\beta$-emission SPND) or $\gamma$-quanta emission (Compton SPND). $\gamma$-Quanta are converted into electrons and thus a signal is formed. Conversion in Compton SPND occurs due to the interaction of $\gamma$-quanta with detector materials in the processes of Compton scattering, photoelectric effect and electron-positron pair production. Thus, electrons are emitted from the emitter, a potential difference arises between the collector and the emitter, which leads to the flow of an electric current in the circuit [26].

It is known that $\beta$-emission detectors have a certain inertia (up to several minutes) [20, 27 - 30]. In [1] the model of rhodium SPND signal generation is considered. For the case of changes in the average values of neutron flux densities in the WWER 
reactor from larger to lower values and vice versa, a calculation was performed. Calculation demonstrates that the time for equilibration in the processes of atoms activation and decay (associated with the signal formation) is at the level of $\sim 300 \mathrm{~s}$. Such a signal delay makes it difficult (or eliminates) the possibility of using a rhodium detector in modes with fast fluctuations in neutron flux densities. At present, work is underway to optimize $\beta$-emission SPND in such a way as to reduce the response time of the detector. Mostly, this is done by reconsidering the geometry of the detector, inputting other additional detectors, developing new software.

However, even the best advances in the modification of $\beta$-emission SPNDs can not be compared with the fact that the Compton detector already has the necessary instantaneous response (the inertia of the signal is in essence determined by the RC-circuits of the measuring chains) [31].

The main processes responsible for the formation of the Compton-type SPND signal are shown on Fig. 1: $\Phi_{\mathrm{n}}^{\mathrm{R}}$ is the flow of thermal and epithermal neutrons in the reactor core; $\Phi_{\gamma}^{\mathrm{R}}=\Phi_{\gamma}^{\mathrm{inst}}+\Phi_{\gamma}^{\mathrm{del}}$ is the reactor $\gamma$-radiation; $\Phi_{\gamma}^{\text {inst }}$ is the flux of instant $\gamma$ quanta emitted during fuel nuclei fission; $\Phi_{\gamma}^{\mathrm{del}}$ is the flux of delayed $\gamma$-quanta emitted when the excitation energy of fission products nucleus are removed; $\mathrm{C}$ is the collector; $\mathrm{E}$ is the emitter (in our case is $\mathrm{Hf}$ ); $\mathrm{I}$ is the insulator. The numbers indicate the processes responsible for signal generation:

1 - in the reaction $(n, \gamma)$, the neutron is captured by the atom of the insulator material, the $\gamma$-quantum emitted in this process takes part in the $\gamma$-e process (Compton scattering, pair-formation $\mathrm{e}^{-}-\mathrm{e}^{+}$, photoelectric effect) inside the insulator layer;

$2-$ in the reaction $(n, \gamma)$, the neutron is captured by the atom of the emitter material, the $\gamma$-quantum emitted in this process takes part in the $\gamma$-e process inside the insulator layer;
3 - in the reaction $(n, \gamma)$, the neutron is captured by the atom of the emitter material, the $\gamma$-quantum emitted in this process takes part in the $\gamma$-e process inside the emitter layer;

4 - in the reaction $(n, \gamma)$, the neutron is captured by the atom of the insulator material, the $\gamma$-quantum emitted in this process takes part in the $\gamma$-e process inside the emitter layer;

5 - reactor $\gamma$-quantum participates in the $\gamma$-e process inside the insulator layer;

6 - reactor $\gamma$-quantum participates in the $\gamma$-e process inside the emitter layer.

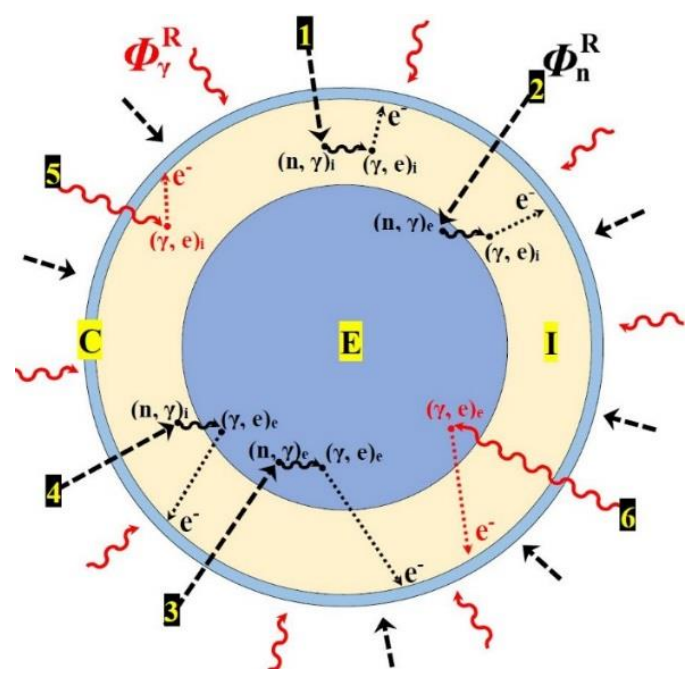

Fig. 1. Schematic representation of the main processes responsible for the Compton SPND signal formation.

If we generalize the foregoing, we see that the electrons in the detector are produced, mainly because of the three "sources" of gamma radiation on Fig. 2: 1) the instantaneous $\gamma$-radiation in the fission of nuclear fuel; 2) the instantaneous $\gamma$-radiation generated during the excitation removal in compound nuclei of SPND's materials atoms; 3 ) the $\gamma$-radiation of fission products (delayed $\gamma$-radiation).

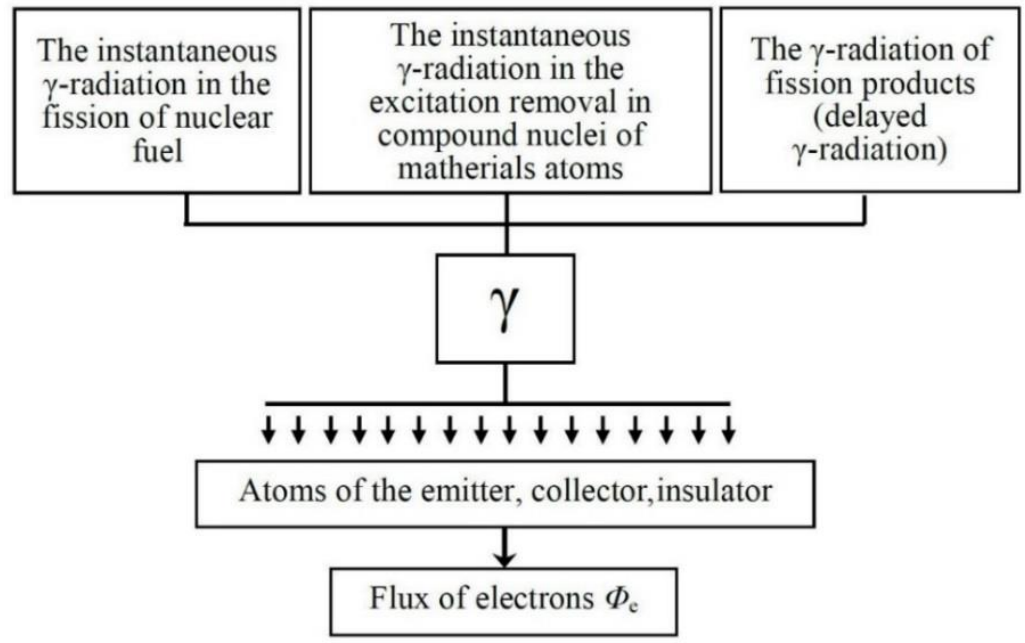

Fig. 2. Schematic representation of the formation process of an electron flux in a Compton SPND. 
Each of the "sources" has its own flux density and its own energy spectrum, which, as a result, determines the SPND total signal.

The "instantaneous" action of the Compton detector is determined by the lifetime of the compound (intermediate, compound) nucleus $(A+1$, $Z)^{*}$, which is in an excited state after the neutron capture by the initial nucleus $(A, Z)$

$$
(A, Z)+\mathrm{n} \rightarrow(A+1, Z)^{*} \rightarrow(A+1, Z)+\gamma,
$$

where $A$ is the atomic weight; $Z$ is the nucleus charge; $\mathrm{n}$ is the neutron; $\gamma$ is the $\gamma$-quantum. For heavy nuclei, this time has a value of the order of $\sim 10^{-14}$ s [32]. I.e., the signal delay will be determined only by this time. In a Compton neutron detector, only a part of the signal can be formed with a delay, which is due to half-lives of the existing isomeric (metastable) states (if they appear, as, for example, in $\mathrm{Hf}$ ) [1].

Thus, for the new SPND in the RCSS system, the issue of a signal delay is removed by using the Compton detector. It remains to develop or select a material that would not only be a good $\gamma$-emitter by its characteristics, but would also meet the requirements for radiation and mechanical properties. In our opinion, the material that fully meets the emerging requirements is the metallic hafnium.

\section{Radiation properties of hafnium}

The materials ability to maintain integrity and geometric dimensions during irradiation is the basic criterion for their radiation resistance. The characteristics of hafnium vary little in the conditions of the reactor core $[3,4,12,33]$. Structural damage of this material during reactor irradiation manifests itself mainly in the change of dislocation structure, accumulation of transmutants and hydrogenation of the material.

From the position of choosing the emitter material for the SPND, hafnium is interesting in its ability to absorb neutrons and emit $\gamma$-quanta. The preservation of these properties is realized due to the fact that the isotopes of hafnium have high values of the cross-section for the radiative capture of thermal and resonant neutrons, and follow one by one in a sequence of mass numbers $A=176 \ldots 180$. Under the influence of neutrons, a radiative redistribution of the isotope composition occurs - the $\mathrm{i}$-th isotope is transformed (converted) into (i+1)-th, and so on until the isotope of ${ }^{180} \mathrm{Hf}$ is reached. Isotope ${ }^{180} \mathrm{Hf}$ has a small value of the radiative capture crosssection in the (n, $\gamma)$-reaction. Thus, the rate of appearance of this isotope by far exceeds its depletion rate. This fact determines an insignificant change in the elemental composition of the hafnium emitter $[2,34,35]$. In comparison with other popular emitter materials, hafnium has a huge advantage in terms of burn-out. For example, at neutron flux of $\sim 10^{14} \mathrm{n} /\left(\mathrm{cm}^{2} \cdot \mathrm{s}\right)$ in a 1 year operation, $19 \%$ of the silver emitter burns out, and $34 \%$ of rhodium [22]. Burn-out rate calculation for hafnium atoms at the same conditions $\left(\Phi_{\mathrm{n}} \sim 10^{14} \mathrm{n} /\left(\mathrm{cm}^{2} \cdot \mathrm{s}\right) ; \quad \gamma=0.12\right.$; emitter diameter $-0.5 \ldots 2 \mathrm{~mm})$ gives value not exceeding $1.5 \%$. Of course, this state of affairs is provided by the transformation of the hafnium isotopes into each other. Moreover, the fact that the elemental composition of the emitter from hafnium varies little with time, it is very important from the point of conservation (or small change) of the attenuation (absorption) coefficients of $\gamma$-radiation. The detector signal is generated by electrons, which appear in the $\gamma$-radiation attenuation.

In the burning-out process of the hafnium isotopes atoms the transmutant atoms are formed. From the position of preserving the ability to absorb neutrons and emit $\gamma$-quanta, the most important is the production of isotopes ${ }^{181,182,183} \mathrm{Ta}$ and ${ }^{182,183,184} \mathrm{~W}$. Some of them have high cross-sections in $(\mathrm{n}, \gamma)$ reaction (Table) and gradually compensate for the absorbing ability loss of the hafnium matrix. The appearance of transmutant atoms significant number is limited by ${ }^{184} \mathrm{~W}$, because its rate of further transformation is very small $\left(\lambda \sim 10^{-10} \mathrm{~s}^{-1}\right.$ because $\left.\sigma_{\mathrm{W}-184} \approx 8.29 \mathrm{~b}\right) \quad[2,35]$. When calculating the absorption cross-sections in (n, $\gamma$ )-reactions (see Table), the resonance absorption, $k \cdot T$ and Westkott $g$-factor was taken into account. Also the averaged values of the neutron spectrum parameters in the WWER-1000 were used: the neutron flux $5.291 \cdot 10^{13} \mathrm{n} /\left(\mathrm{cm}^{2} \cdot \mathrm{s}\right.$ ) (at the calculation of the $\lambda$ ); the hardness of the neutron spectrum -0.436 . The selfshielding factor (the distortion of the neutron spectrum with the advance into the material) for the emitter wasn't accounted for.

\begin{tabular}{|c|c|c|c|}
\hline$k T(6$ & $\begin{array}{l}\text { thermal neu } \\
\text { th considerin } \\
\mathrm{K}) \text {; spectrum } \\
\mathrm{We}\end{array}$ & $\begin{array}{l}\text { n capture cross sect } \\
\text { f: resonance integra } \\
\text { ardness ratio } \frac{\Phi_{\text {res }}}{\Phi_{\text {th }}}= \\
\text { ott } g \text {-factor }\end{array}$ & $\begin{array}{l}\text { ns } \\
I ; \\
0.436 ;\end{array}$ \\
\hline Element & $\begin{array}{c}\text { Atomic } \\
\text { mass, a.m.u }\end{array}$ & $\begin{array}{c}\text { Natural } \\
\text { composition [38], } \\
\text { at. } \%\end{array}$ & $\sigma, \mathrm{b}$ \\
\hline \multirow{7}{*}{$\mathrm{Hf}$} & 174 & 0.16 & 496.65 \\
\hline & 176 & 5.26 & 318.65 \\
\hline & 177 & 18.6 & 3395.57 \\
\hline & 178 & 27.28 & 887.77 \\
\hline & 179 & 13.62 & 245.94 \\
\hline & 180 & 35.08 & 20.71 \\
\hline & 181 & & 107.3 \\
\hline \multirow{2}{*}{$\mathrm{Ta}$} & 181 & & 300.78 \\
\hline & 182 & & 17290.74 \\
\hline \multirow{3}{*}{ W } & 182 & & 286.37 \\
\hline & 183 & & 154.34 \\
\hline & 184 & & 8.29 \\
\hline
\end{tabular}


Thus, in the hafnium of the natural composition, the atoms of its isotopes (which transform into one another) and the atoms of the transmutants' isotopes participate in the (n, $\gamma)$ - and $\gamma$-e-processes (reactions). All this allows hafnium to be a good $\gamma$ emitter of the Compton SPND for a long time (the operation time directly depends on the flux density and the hardness of the neutron spectrum).

\section{Conclusion}

The paper considers the atomic energy development questions, which raise interest in the use of hafnium as an emitter of the Compton SPND for thermal and resonant neutrons. The prospects of using hafnium in the in-reactor measurement systems are shown as one of the ways to improve the reactors' safety and efficiency. Based on the performed calculations, the advantages (instant response, prolonged operation life, absorbing properties recovery) of a Compton SPND with an emitter of metallic hafnium are demonstrated in comparison with the $\mathrm{HfO}_{2}$-based Compton detector and the commonly-used $\beta$-emissive detectors.

\section{REFERENCES}

1. B.A. Shilyaev et al. Compton detector of neutrons for the energy yield control in the active zone of WWER. Problems of Atomic Science and Technologies (PAST) 2(108) (2017) 75.

2. B.A. Shilyaev et al. Hafnium in Nuclear Power Industry: The Evolution of Increasing of the Economic Indicators and the Operation Safety of Pressurized Water Nuclear Reactors. Problems of Atomic Science and Technologies (PAST) 1(113) (2018) 43.

3. K.V. Kovtun et al. Hafnium - a material for the system of excess reactivity compensation in nuclear power reactors. Problems of Atomic Science and Technology (PAST) 2(84) (2013) 118.

4. V.D. Risovanyi et al. Parameters and Structure of the Primary Radiation Damage of Hafnium in the Core of a Nuclear Reactor. Materials of Scientific Conf. "New Materials for Innovation Development of Nuclear Power Engineering”, Dmitrovgrad, Russia, March 24 27, 2014 (Dmitrovgrad, 2014) 18. (Rus)

5. Yu.M. Semchenkov, V.A. Mil'to, B.E. Shumskii. Incorporation of the procedure for monitoring coolant boiling in a VVER-1000 core into the in-reactor noise diagnostics system. Atomic Energy 105(2) (2008) 99.

6. Yu.M. Semchenkov et al. Analysis of neutron flux noise due to coolant parameter fluctuations in a VVER core. Atomic Energy 103(5) (2007) 845.

7. P.A. Ponomarenko, M.A. Frolova, N.N. Lenivenko. Influence of surface boiling with underheating on the state of a boiling surface. Global Nuclear Safety 1(18) (2016) 60. (Rus)

8. P.E. Blomberg. Reactor physics problems concerning the startup and operation of power reactors. Technical reports series No. 143 "Developments in the Physics of Nuclear Power Reactors” (Vienna, IAEA, 1973) p. 183.

9. V.I. Karnachuk. Automatic Neutron Flux Equalization Systems in Nuclear Reactors (Tomsk Polytechnic University, 2009) 221 p. (Rus)

10. V.I. Mitin, V.F. Shikalov, S.A. Tsimbalov. Experimental study of current formation in direct charge detectors with an emitter from rhodium. Sov. Atomic Energy 34 (1973) 376.

11. W.H. Todt, Sr. Characteristics of self-powered neutron detectors used in power reactors. Proc. of specialists' meeting "In-core instrumentation and core assessments", Mito-spi, Japan, 14 - 16 Oct. 1996 (Paris: Nuclear Energy Agency: Organisation for Economic Co-operation and Development, 1997) p. 181.

12. V.D. Risovanyi, E.P. Klochkov, V.B. Ponomarenko. Hafnium in Nuclear Power Engineering (Dimitrovgrad:
NIIAR, 1993) 143 p. (Rus)

13. D. Gosset. Absorber Materials for Generation IV Reactors. Woodhead Publishing Series in Energy: Number 106. Structural Materials for Generation IV Nuclear Reactors. (Ed. P. Yvon). (Elsevier, 2017) p. 533.

14. J. Giacobbe, D.N. Dunning. New Developments in the Fabrication of Hafnium Control Rods. Nucl. Sci. Eng. 4 (1958) 467.

15. G.W. Cunningham et al. Development of a Composite Control Rod. Nucl. Sci. Eng. 4 (1958) 449.

16. Absorbent Materials for the Regulation of Nuclear Reactors. Trans. from Eng. under ed. B.G. Arabey, V.V. Chekunov (Moskva: Atomizdat, 1965) 450 p. (Rus)

17. E.P. Klochkov, V.D. Risovanyi. Hafnium in nuclear power engineering. Nuclear Technology Abroad 10 (1987) 12. (Rus)

18. M.G. Mitelman, N.D. Rozenblum. Charge Detectors of Ionizing Radiations (Moskva: Energoatomizdat, 1982) 78 p. (Rus)

19. I.Ya. Emelyanov et al. Radiation-thermal tests of Compton emission neutron detectors with an emitter containing hafnium. Atomic Energy 54(3) (1983) 198.

20. Yu.I. Volodko et al. Tests of Compton neutron detectors with an emitter containing hafnium in RBMK reactors. Atomic Energy 62(6) (1987) 472.

21. A.Yu. Kondakov et al. Factory calibration of in-core detectors. Materials of the 16th annual scientific and technical "Conference of Young Specialists on Nuclear Power Plants". OKB "Hydropress", 26 - 27 March, 2014. (Rus)

22. I.Ya. Emelyanov, V.V. Postnikov, Yu.I. Volodko. Power distribution monitoring and control for a RBMK reactor. Sov. Atomic Energy 48(6) (1980) 360.

23. I.V. Shamanin, A.V. Kiselev, V.A. Luzko. Monitoring of the energy release field during the operation of a nuclear reactor using direct charge detectors. Proc. of Tomsk Polytechnic University 316(2) (2010) 67. (Rus)

24. A.S. Gerasimov, T.S. Zaritskaya, A.P. Rudyk. Handbook on the Formation of Nuclides in Nuclear Reactors (Moskva: Energoatomizdat, 1989) 575 p. (Rus)

25. I.N. Nigmatulin, B.I. Nishamatulin. Nuclear Power Plants (Moskva: Energoatomizdat, 1986) 168 p. (Rus)

26. M.G. Mitelman, R.S. Erofeev, N.D. Rozenblyum. Transformation of the energy of short-lived radioactive isotopes. Sov. J. Atomic Energy 10(1) (1961) 70. 
27. P.S. Rao, S.C. Misra. Neutron sensitivity of vanadium self-powered neutron detectors. Nucl. Instrum. Meth. A 253(1) (1986) 57.

28. O. Moreira, H. Lescano. Analysis of vanadium selfpowered neutron detectors signal. Annals of Nuclear Energy 58 (2013) 90.

29. V. Verma. Development of a Neutron Flux Monitoring System for Sodium-cooled Fast Reactors. Digital Comprehensive Summaries of Uppsala Dissertations from the Faculty of Science and Technology 1508 (Uppsala: Acta Universitatis Upsaliensis, 2017) 70 p.

30. H. Böck, J. Rantanen. Temperature and radiation tests with Pt- and Rh-self-powered neutron detectors. Nuclear Instruments and Methods 164(1) (1979) 205.

31. H.D. Warren, N.H. Shah. Neutron and Gamma-Ray Effects on Self-Powered In-Core Radiation Detectors. Nucl. Science and Engineering 54 (1974) 395.
32. K.N. Mukhin. Experimental Nuclear Physics. Vol. 1: Physics of the Atomic Nucleus (Moskva: Atomizdat, 1974) 584 p. (Rus)

33. N.N. Belash et al. Analysis of construction developments and materials of RCSS AA AE of increased working capacity. Nuclear and Radiation Technology 7(3-4) (2007) 18. (Rus)

34. B.A. Shilyaev et al. The sequential conversion of hafnium isotopes upon irradiation in the core of the WWER-1000 nuclear reactor. Preprint NSC KIPT. KIPT 2017-1 (Kharkov, 2017) 32 p. (Rus)

35. B.A. Shilyaev et al. Basics of a new Compton SPND development for the core of a WWER-1000 nuclear reactor. Preprint NSC KIPT. KIPT 2017-2 (Kharkov, 2017) 46 p. (Rus)

36. http://www.ciaaw.org/isotopic-abundances.htm

\section{О. Л. Улибкін ${ }^{1, *}$, О. В. Рибка ${ }^{1}$, К. В. Ковтун ${ }^{1}$, В. Є. Кутній ${ }^{1}$ В. М. Воєводін ${ }^{1,2}$, О. О. Пудов ${ }^{1}$ \\ ${ }^{1}$ Національний науковий центр «Харківський фізико-технічний інститут», «Інститут фізики твердого тіла, матеріалознавства та технологій», Харків, Україна \\ ${ }^{2}$ Харківський національний університет ім. В. Н. Каразіна}

*Відповідальний автор: a.ulybkin@gmail.com

\section{КОМПТОН-ЕМІСІЙНИЙ ДЕТЕКТОР НЕЙТРОНІВ ІЗ ГАФНІЮ ДЛЯ ВНУТРІШНЬОРЕАКТОРНОГО КОНТРОЛЮ}

Обгрунтувано застосування металевого гафнію в якості емітера комптонівських внутрішньореакторних детекторів теплових і резонансних нейтронів. Розглянуто основні тенденції в розвитку атомної енергетики, що піднімають інтерес до використання гафнію. Узагальнено відомі дані про особливості функціонування як комптонівських, так і $\beta$-емісійних детекторів прямого заряду. Розглянуто механізми формування сигналу комптонівського детектора, що знаходиться в потоках реакторних нейтронів і $\gamma$-квантів. Наведено результати розрахунку ступеня вигоряння атомів гафнію для умов реакторів РБМК і ВВЕР. Розглянуто дію «джерел» $\gamma$-випромінювання, що реалізують найбільший внесок у народження електронів у детекторі.

Ключові слова: ядерна енергетика, детектор нейтронів, гафній, миттєвий відгук, енерговиділення, контроль, радіаційний ресурс.

\section{А. Л. Улыбкин ${ }^{1, *}$, А. В. Рыбка ${ }^{1}$, К. В. Ковтун ${ }^{1}$, В. Е. Кутний ${ }^{1}$, В. Н. Воеводин ${ }^{1}$, А. О. Пудов \\ ${ }^{1}$ Нацииональный научный изентр «Харьковский физико-технический институт», «Институт физики твердого тела, материаловедения и технологий», Харьков, Украина \\ ${ }^{2}$ Харьковский национальный университет им. В. Н. Каразина}

*Ответственный автор: a.ulybkin@gmail.com

\section{КОМПТОН-ЭМИССИОННЫЙ ДЕТЕКТОР НЕЙТРОНОВ ИЗ ГАФНИЯ ДЛЯ ВНУТРИРЕАКТОРНОГО КОНТРОЛЯ}

Работа посвящена обоснованию применения металлического гафния в качестве эмиттера комптоновских внутриреакторных детекторов тепловых и резонансных нейтронов. Рассмотрены основные тенденции в развитии атомной энергетики, поднимающие интерес к использованию гафния. Обобщены известные данные об особенностях функционирования как комптоновских, так и $\beta$-эмиссионных детекторов прямого заряда. Рассмотрены механизмы формирования сигнала комптоновского детектора, находящегося в потоках реакторных нейтронов и $\gamma$-квантов. В работе приведен результат расчета степени выгорания атомов гафния для условий реакторов РБМК и ВВЭР. Рассмотрено действие «источников» $\gamma$-излучения, реализующих наибольший вклад в рождение электронов в детекторе.

Ключевые слова: ядерная энергетика, детектор нейтронов, гафний, мгновенный отклик, энерговыделение, контроль, радиационный ресурс. 